\title{
Isotherm investigation for the sorption of fluoride onto Bio-F: comparison of linear and non-linear regression method
}

\author{
Manish Yadav ${ }^{1}$ Nitin Kumar Singh ${ }^{2}$
}

Received: 2 August 2016/Accepted: 24 July 2017/Published online: 1 August 2017

(c) The Author(s) 2017. This article is an open access publication

\begin{abstract}
A comparison of the linear and non-linear regression method in selecting the optimum isotherm among three most commonly used adsorption isotherms (Langmuir, Freundlich, and Redlich-Peterson) was made to the experimental data of fluoride $(\mathrm{F})$ sorption onto Bio-F at a solution temperature of $30 \pm 1{ }^{\circ} \mathrm{C}$. The coefficient of correlation $\left(r^{2}\right)$ was used to select the best theoretical isotherm among the investigated ones. A total of four Langmuir linear equations were discussed and out of which linear form of most popular Langmuir-1 and Langmuir-2 showed the higher coefficient of determination (0.976 and 0.989) as compared to other Langmuir linear equations. Freundlich and Redlich-Peterson isotherms showed a better fit to the experimental data in linear least-square method, while in non-linear method Redlich-Peterson isotherm equations showed the best fit to the tested data set. The present study showed that the non-linear method could be a better way to obtain the isotherm parameters and represent the most suitable isotherm. Redlich-Peterson isotherm was found to be the best representative ( $\left.r^{2}=0.999\right)$ for this sorption system. It is also observed that the values of $\beta$ are not close to unity, which means the isotherms are approaching the Freundlich but not the Langmuir isotherm.
\end{abstract}

Nitin Kumar Singh

nitin261187@gmail.com

Manish Yadav

manishyadavonline@gmail.com

1 Department of Civil Engineering, Malviya National Institute of Technology, Jaipur, Rajasthan 302017, India

2 Department of Civil Engineering, Indian Institute of Technology, Roorkee, Uttarakhand 247667, India
Keywords Sorption · Bio-F · Fluoride - Equilibrium isotherm · Linear regression · Non-linear regression

$\begin{array}{ll}\text { Abbreviations } \\ \mathrm{F} & \text { Fluoride } \\ \text { Bio-F } & \text { Bio-filter } \\ r^{2} & \text { Coefficient of correlation } \\ \mathrm{NaF} & \text { Sodium fluoride } \\ \mathrm{mg} & \text { Milligramme } \\ \mathrm{g} / \mathrm{L} & \text { Gramme per litre } \\ \mathrm{mg} / \mathrm{L} & \text { Milligramme per litre } \\ { }^{\circ} \mathrm{C} & \text { Degree centigrade } \\ \mathrm{HDPE} & \text { High-density polyethylene } \\ \mathrm{K}_{\mathrm{L}} & \text { Adsorption equilibrium constant } \\ Q_{\mathrm{m}} & \text { Maximum adsorption capacity } \\ q_{\mathrm{e}} & \text { Adsorbate adsorbed onto adsorbent } \\ C_{\mathrm{e}} & \text { Equilibrium liquid-phase concentration } \\ K_{\mathrm{F}} & \text { Freundlich constant } \\ 1 / n & \text { Heterogeneity factor } \\ K_{\mathrm{R}} & \text { Redlich-Peterson constant } \\ a_{\mathrm{R}} & \text { Redlich-Peterson constant } \\ \beta & \text { Redlich-Peterson constant } \\ q_{\mathrm{m}} & \text { Equilibrium capacity }\end{array}$

\section{Introduction}

Among the various methods used for defluoridation of drinking water, the adsorption process has been widely used because of its simplicity, affordability, easy operation, and satisfactory results (Liu et al. 2010; Deng et al. 2011; Bhatnagar et al. 2011; Xiang et al. 2014). Adsorption process includes the selective transfer of solute 
components onto the surface or the bulk of solid adsorbent materials in the aqueous phase (Kumar and Sivanesan 2007). The effectiveness of an adsorbent is estimated on the basis of its uptake capacity, adsorption rate, mechanical strength, possibility of regeneration, and reuse options (Tang and Zhang 2016). Among these, adsorbent capacity is the most important parameter which plays a vital role in overall process of adsorption (Oh and Park 2002; Gong et al. 2005). The uptake capacity and adsorption performance are usually determined on the basis of equilibrium experiments and sorption isotherms describing the interaction of pollutant with the adsorbent material (Brdar et al. 2012). The equilibrium studies are also very important in optimizing the design parameters for any adsorption system which provide sufficient information about physicochemical data to evaluate the adsorption process as a unit operation (Leyva-Ramos et al. 2010). The distribution of a solute between solid adsorbent and liquid phase is also a measure of the position of equilibrium. Therefore, equilibrium data should be accurately fit into different isotherm models to find a suitable one that can be used to design the process (Khaled et al. 2009).

Among the various tested isotherms for the defluoridation of drinking water, Langmuir, Freundlich, and RedlichPeterson isotherms are frequently used over a wide concentration range of solute and sorbent to describe the adsorption equilibrium for water and wastewater treatment applications (Ho et al. 2005; Ho 2006a, b; Kumar and Sivanesan 2007).

The conventional approach for parameter evaluation of non-linear forms of aforementioned isotherms involves linearization of the expressions through transformation, followed by the linear regression method. The main disadvantage of the linear regression technique, that limit its use, includes estimation of only two variables in an empirical equation; whereas, non-linear optimization provides a more complex, yet mathematically rigorous method to determine the isotherm parameter values (Pal et al. 2013).

Linear regression analysis has been frequently employed in accessing the quality of fits and adsorption performance for fluoride removal from aqueous solutions (Fan et al. 2003; Onyango et al. 2004; Kamble et al. 2009; Foo and Hameed 2010). The fitting validity of different models was tested in linearized forms using coefficient of determination. Some other methods, recently were reported to predict the optimum isotherm, which includes correlation coefficient, the sum of errors squared, a hybrid error function, Spearman's correlation coefficient, Standard deviation of relative errors, coefficient of non-determination Marquardt's percent standard deviation, the average relative error, and the sum of absolute errors (Kumar et al. 2008; Foo and Hameed 2010). Currently, non-linear regression method is observed to be the best way in selecting the optimum isotherm, but very limited published literature is available for such type of adsorption systems, i.e., Bio-F-F system. This method of non-linear regression involves the step of minimizing the error distribution between the experimental equilibrium data and predicted isotherm (Krishni et al. 2014).

Having these considerations in mind, a comparison of linear least squares method and non-linear regression method was discussed in present study using the experimental adsorption data of $\mathrm{F}$ onto Bio-F. The three widely used isotherms (Langmuir, Freundlich, and RedlichPeterson) were investigated to discuss this issue. A trialand-error optimization method was used for the non-linear regression using the solver add-in function, Microsoft Excel, Microsoft Corporation (Kumar and Sivanesan 2007; Krishni et al. 2014). In order to solve the non-linear equations of applied isotherms, an efficient Microsoft's add-in software xlstat is used in this study (Shahmohammadi-Kalalagh and Babazadeh 2014; Kausar et al. 2014). This study was done in continuation of our previous work (Yadav et al. 2014, 2015) to examine the most suitable isotherm for Bio-F and F system using linear and nonlinear equations.

\section{Experimental programmes}

\section{Materials and methods}

All chemicals used throughout this study were of analytical grade and purchased mainly from Merck India Limited. The stock solution of fluoride was prepared by dissolving the appropriate amount $(221 \mathrm{mg})$ of anhydrous $\mathrm{NaF}$ in $1 \mathrm{~L}$ of double-distilled water to a concentration of $100 \mathrm{mg} / \mathrm{L}$. The test working solutions of $\mathrm{F}$ were prepared by successive dilution with double-distilled water. All the batch adsorption studies were undertaken using Bio-F adsorbent, manufactured by HES Water Engineers (I) Pvt. Ltd. (a joint venture company of water engineers, Australia). More details about this adsorbent are given in our previous studies (Yadav et al. 2014, 2015).

Batch equilibrium adsorption experiments were conducted to investigate the adsorption behaviour of Bio-F at a constant dose of $10 \mathrm{~g} / \mathrm{L}$ and varying concentrations of fluoride. All the adsorption experiments were carried out at room temperature of $30 \pm 1{ }^{\circ} \mathrm{C}$. To study the various process parameters, a series of conical flasks having test solution and adsorbent, was then shaken at a constant speed of $90 \mathrm{rpm}$ in an orbital shaker with thermostatic control (Remi, India). At the end of the required contact time (when equilibrium was achieved), flasks were removed from the shaker and allowed to stand for $5 \mathrm{~min}$ for the 
Table 1 Selected adsorption isotherms and their linear forms with corresponding plots

\begin{tabular}{|c|c|c|c|}
\hline \multicolumn{2}{|c|}{ Isotherm model (non-linear form) } & \multirow{2}{*}{$\begin{array}{l}\text { Linear form } \\
C_{\mathrm{e}} / q_{\mathrm{e}}=\frac{1}{q_{\mathrm{m}}} C_{\mathrm{e}}+\frac{1}{K_{\mathrm{L}} q_{\mathrm{m}}}\end{array}$} & \multirow{2}{*}{$\frac{\text { Plot }}{C_{\mathrm{e} / q_{\mathrm{e}}} \text { vs } C_{\mathrm{e}}}$} \\
\hline Langmuir 1 & $q_{\mathrm{e}}=\frac{Q_{\mathrm{m}} K_{\mathrm{L}} C_{\mathrm{e}}}{1+K_{\mathrm{L}} C_{\mathrm{e}}}$ & & \\
\hline Langmuir 2 & & $\frac{1}{q_{\mathrm{e}}}=\left(\frac{1}{K_{\mathrm{L}} q_{\mathrm{m}}}\right) \frac{1}{C_{\mathrm{e}}}+\frac{1}{q_{\mathrm{m}}}$ & $\frac{1}{q_{\mathrm{e}}}$ vs $\frac{1}{C_{\mathrm{e}}}$ \\
\hline Langmuir 3 & & $q_{\mathrm{e}}=q_{\mathrm{m}}-\left(\frac{1}{K_{\mathrm{L}}}\right) \frac{q_{\mathrm{e}}}{C_{\mathrm{e}}}$ & $q_{\mathrm{e}} \operatorname{vs} \frac{q_{\mathrm{e}}}{C_{\mathrm{e}}}$ \\
\hline Langmuir 4 & & $\frac{q_{\mathrm{e}}}{C_{\mathrm{e}}}=K_{\mathrm{L}} q_{\mathrm{m}}-K_{\mathrm{L}} q_{\mathrm{e}}$ & $\frac{q_{\mathrm{e}}}{C_{\mathrm{e}}}$ vs $q_{\mathrm{e}}$ \\
\hline Freundlich & $q_{\mathrm{e}}=K_{\mathrm{F}} C_{\mathrm{e}}^{1 / n}$ & $\log q_{\mathrm{e}}=\log K_{\mathrm{F}}+\frac{1}{n} \log C_{\mathrm{e}}$ & $\log q_{\mathrm{e}}$ vs $\log C_{\mathrm{e}}$ \\
\hline Redlich-Peterson & $q_{\mathrm{e}}=\frac{K_{\mathrm{R}} C_{\mathrm{e}}}{1+a_{\mathrm{R}} C_{\mathrm{e}}^{\beta}}$ & $\ln \left(K_{\mathrm{R}} \frac{C_{\mathrm{e}}}{q_{\mathrm{e}}}-1\right)=\beta \ln \left(C_{\mathrm{e}}\right)+\ln \left(a_{\mathrm{R}}\right)$ & $\ln \left(K_{\mathrm{R}} \frac{C_{\mathrm{e}}}{q_{\mathrm{e}}}-1\right)$ vs $\ln \left(C_{\mathrm{e}}\right)$ \\
\hline
\end{tabular}

$K_{\mathrm{L}}$ is the adsorption equilibrium constant $(\mathrm{L} / \mathrm{mg}), K_{\mathrm{F}}$ and $1 / n$ are empirical constants of Freundlich isotherm, $K_{\mathrm{R}}, a_{\mathrm{R}}$ and $\beta(0<\beta<1)$ are three constants of Redlich-Peterson Isotherm

adsorbent to settle down. After the fluoride adsorption equilibrium studies, the treated and untreated samples were filtered through Whatman filter paper No. 42 and stored in HDPE bottles for the further analysis of the residual $\mathrm{F}$ using an ion meter (Thermo Scientific Orion 5-Star ion meter).

\section{Isotherm models}

Equilibrium isotherm equations are used in this study to describe the experimental sorption data of present adsorption system. The equation parameters with the underlying thermodynamic assumptions of these isotherm models often provide an insight into the sorption mechanisms, surface properties, as well as the degree of affinity of the sorbents (Ho 2006a, b). The three most common isotherms for describing solid-liquid sorption systems are Langmuir, Freundlich, and Redlich-Peterson isotherms. Langmuir adsorption isotherm, which was originally developed to describe gas-solid phase adsorption onto activated carbon, has been traditionally used to investigate the performance and potential of different bio-sorbents (Foo and Hameed 2010). This is also valid for adsorption of solutes from aqueous solutions, as monolayer adsorption on specific homogenous sites (a finite number of identical sites) within the adsorbent surface. Therefore, the Langmuir isotherm model estimates the maximum adsorption capacity achieved from complete monolayer coverage on the adsorbent surface (Nur et al. 2014). The Freundlich isotherm is an empirical model, which is the earliest known relationship describing the adsorption process. It is applicable to the gas-solid phase non-ideal and multilayer adsorption on heterogeneous surfaces with interaction between adsorbed molecules. It also suggests that sorption energy exponentially decreases upon the completion of adsorption process. Therefore, Freundlich isotherm can be applied to describe the heterogeneous adsorption systems
(Ghorai and Pant 2005). The Redlich-Peterson isotherm, which contains three parameters, $K_{\mathrm{R}}, a_{\mathrm{R}}$ and $\beta$, also includes the features of Langmuir and Freundlich isotherm (Brdar et al. 2012; Khaled et al. 2009). This model has a linear dependence on concentration in the numerator and an exponential function in the denominator to describe adsorption equilibrium over a wide concentration range of adsorbate, thus can be applied for both homogeneous or heterogeneous systems due to its versatility (Foo and Hameed 2010). The non-linear and linear forms of equation of Langmuir, Freundlich, and Redlich-Peterson isotherms are given in Table 1.

\section{Results and discussion}

A trial-and-error procedure was applied to determine the parameters of the investigated isotherms. In this study, the coefficient of determination, $r^{2}$, was used for the experimental data to determine the best-fit isotherm model out of the three used isotherms (Freundlich, Langmuir and Redlich-Peterson). The value of $r^{2}$ for non-linear regression was evaluated using following formula (Ho 2006a, b):

$r^{2}=\frac{\sum\left(q_{\mathrm{m}}-\overline{q_{\mathrm{e}}}\right)^{2}}{\sum\left(q_{\mathrm{m}}-\overline{q_{\mathrm{e}}}\right)^{2}-\sum\left(q_{\mathrm{m}}-q_{\mathrm{e}}\right)^{2}}$,

where $q_{\mathrm{m}}$ is the sorption equilibrium capacity obtained by calculating from the isotherm model, $q_{\mathrm{e}}$ is experimental capacity obtained from experiment, and $\overline{q_{\mathrm{e}}}$ is the average of $q_{\mathrm{e}}$ values.

\section{Linear regression method}

Linear regression is the most commonly used method to determine the best-fit isotherm and the method of least squares has been used for finding parameters of the 

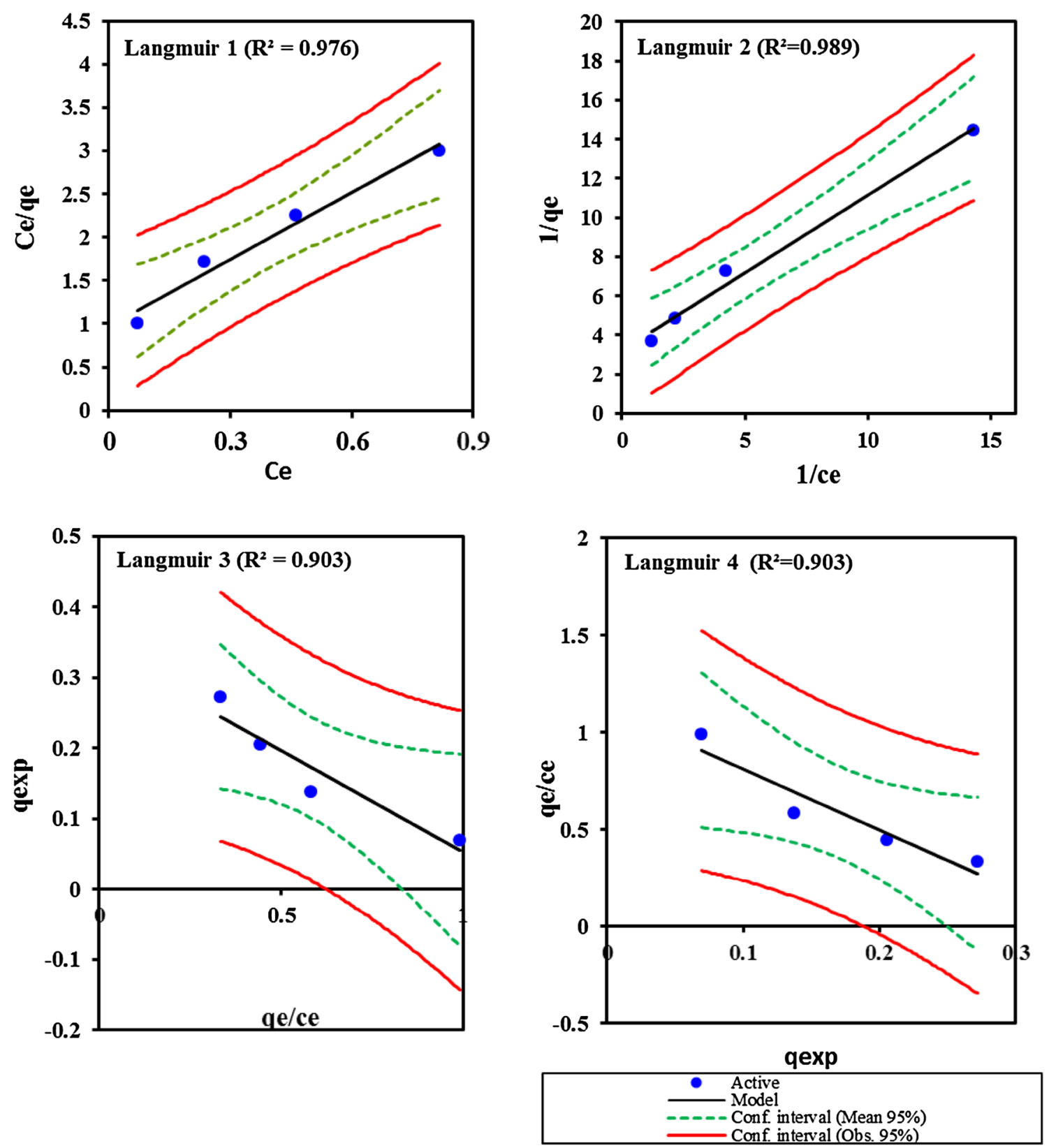

Fig. 1 Different linear forms of Langmuir isotherm obtained using the linear method for the sorption of fluoride onto Bio-F

isotherm models (Krishni et al. 2014; Kausar et al. 2014). It was observed that Langmuir isotherm could be linearized into at least four different forms as in Table 1, and simple linear regression will result in different parameter estimates. The most popular linear forms used are Langmuir-1 and Langmuir-2. The best-fit is obtained using Langmuir-2 because of the minimized deviations from the fitted equation resulting in the best error distribution (Ho 2006a, b). Figure 1 shows the plots of four linear Langmuir equations and the experimental data for the sorption of F onto Bio-F, and it was found that Langmuir-2 isotherm provides a better fit to the experimental equilibrium data.
The applicability of the Freundlich isotherm model was also analysed, using the same set of experimental data, by plotting $\log q_{\mathrm{e}} \mathrm{vs} \log C_{\mathrm{e}}$. Considering the linear forms of Langmuir isotherm for the comparison between the different isotherms, Freundlich isotherm was found to be more suitable as compared to all linear forms of the Langmuir isotherm because of the higher value of coefficient of determination, $r^{2}$. The Freundlich isotherm constants, $K_{\mathrm{F}}, 1 / n$, and coefficients of determination are calculated and shown in Table 2 .

Figure 2 shows the plots of linear Freundlich equations with experimental data for sorption of $\mathrm{F}$ onto Bio-F. The 
Table 2 Isotherm parameters obtained using the linear and non-linear method

\begin{tabular}{|c|c|c|c|c|c|c|c|c|c|c|}
\hline & \multicolumn{3}{|c|}{ Langmuir isotherm } & \multicolumn{3}{|c|}{ Freundlich isotherm } & \multicolumn{4}{|c|}{ Redlich-Peterson isotherm } \\
\hline & $Q_{\mathrm{m}}$ & $K_{\mathrm{L}}$ & $R^{2}$ & $K_{\mathrm{F}}$ & $n$ & $R^{2}$ & $K_{\mathrm{R}}$ & $a_{\mathrm{R}}$ & $\beta$ & $R^{2}$ \\
\hline Linear 1 & 0.39 & 2.7 & 0.976 & 0.31 & 1.79 & 0.999 & 18.8 & 59.94 & 0.45 & 0.999 \\
\hline Linear 2 & 0.31 & 4.01 & 0.989 & & & & & & & \\
\hline Linear 3 & 0.34 & 3.48 & 0.903 & & & & & & & \\
\hline Linear 4 & 0.36 & 3.14 & 0.903 & & & & & & & \\
\hline Non-linear & 0.531 & 0.246 & 0.969 & 0.631 & 1.697 & 0.969 & 20.12 & 64.77 & 0.464 & 0.999 \\
\hline
\end{tabular}

Redlich-Peterson isotherm constants, $K_{\mathrm{R}}, a_{\mathrm{R}}$ and $\beta$, as well as the $r^{2}$ for present adsorption system were obtained using the linear form of isotherm and presented in Table 2.

In all cases the Redlich-Peterson isotherm exhibited the highest coefficient of determinations same as Freundlich isotherm, which provided a considerably better fit as compared to Langmuir but similar to the Freundlich isotherm. It can also be observed that the values of $\beta$ are not close to unity, which means the isotherms are approaching the Freundlich and not the Langmuir. Figure 3 shows the plot of the Redlich-Peterson isotherm equations with the equilibrium experimental data.

\section{Non-linear regression method}

Non-linear regression method is a trial-and-error procedure and is the best way in selecting the optimum isotherm. To perform this, xlstat software is used which is an add-in software with Microsoft's excel spread sheet, Microsoft, and highly efficient than the solver add-in. The abilities of

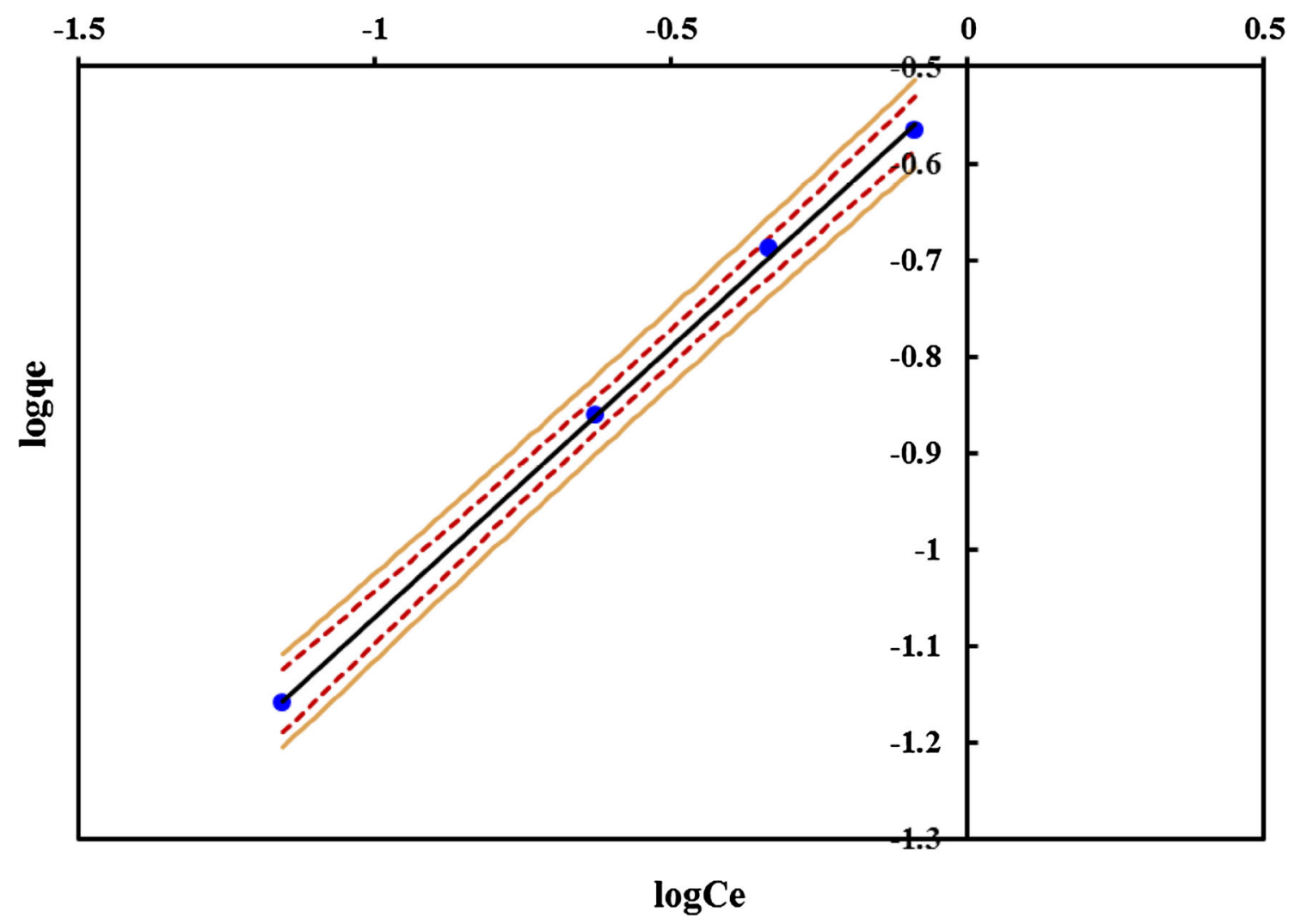

- Active
--- Conf. interval (Mean 95\%)

Model

Conf. interval (Obs. 95\%)

Fig. 2 Freundlich isotherm obtained using the linear method for the sorption of fluoride onto Bio-F 


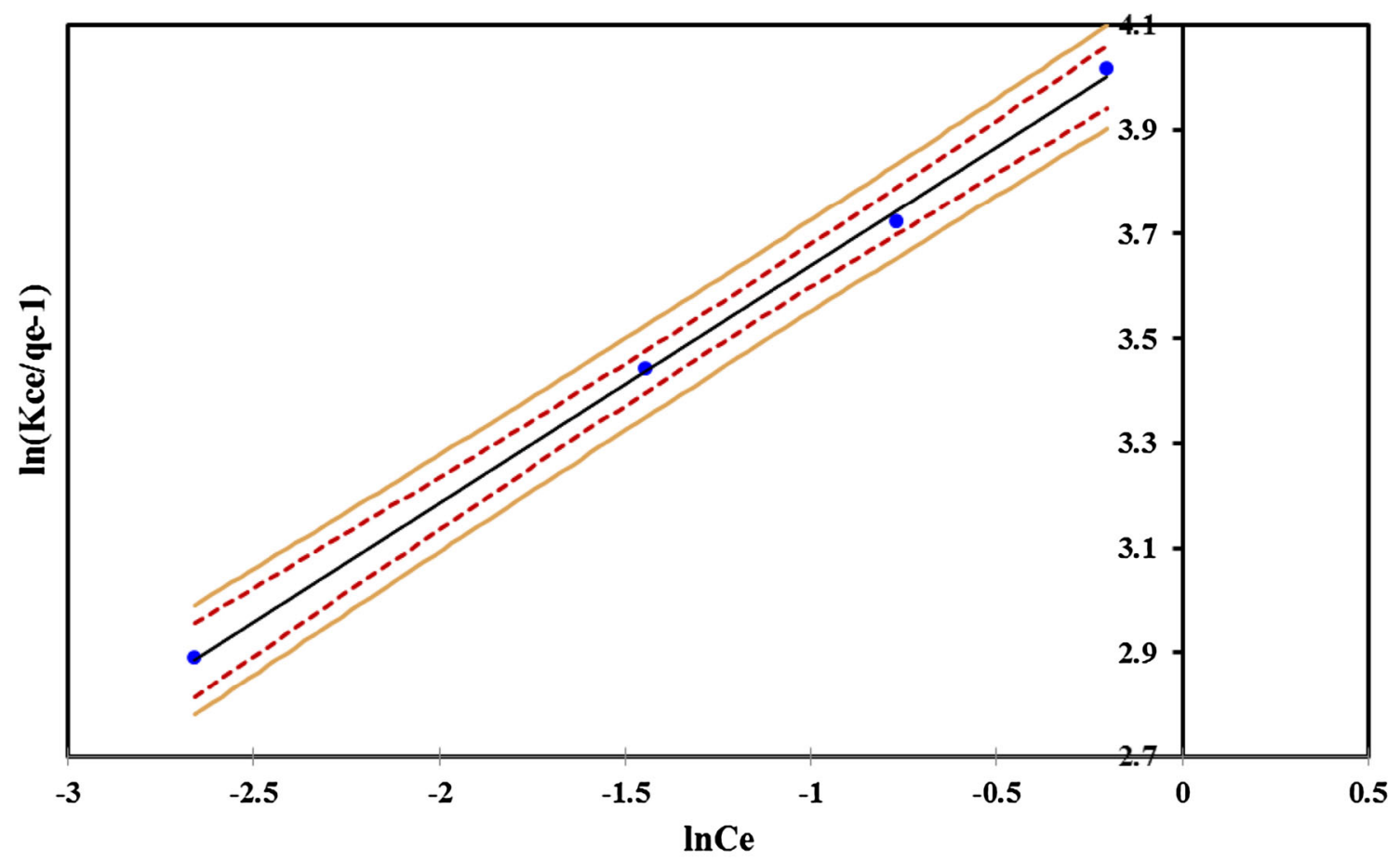

- Active - Model -----Conf. interval (Mean 95\%) - Conf. interval (Obs. 95\%)

Fig. 3 Redlich-Peterson isotherm obtained using the linear method for the sorption of fluoride onto Bio-F

three used isotherms, i.e., Freundlich, Langmuir, and Redlich-Peterson isotherms were examined to model the equilibrium sorption data of fluoride onto Bio-F. The obtained results from the four linear Langmuir equations were observed to be quite similar with each other. When using the non-linear method, there were no problems with non-linear Langmuir isotherm equations as they were in the same error structures. The Langmuir constants obtained from non-linear and linear methods differed even when compared with the results of Langmuir-1 isotherm, which had the highest coefficient of determination for any Langmuir isotherm (Table 2). It seems that the isotherm obtained from Langmuir-1 provided the best fit to the experimental data as compared to other Langmuir linear equations because it had the highest coefficient of determination. The values of Langmuir constants, i.e., $K_{\mathrm{a}}$ and $q_{\mathrm{m}}$ were found to be close to those obtained by using the non-linear method. Figure 4 shows that the RedlichPeterson isotherm, with almost similar coefficients of determination, seems to be the best-fit model for the experimental data. It has been reported that it is inappropriate to use the coefficient of determination of a linear regression analysis to compare the best-fitting models of different isotherms (Ho 2006a, b; Maliyekkal et al. 2006). Inversely, the linear regression has produced a vast amount of different outcomes. Consequently, the Redlich-Peterson isotherm was found to be the best-fit model for the present sorption system. Unlike the linear analysis, a different isotherm would significantly affect the $r^{2}$ value and will have an impact on determination of other parameters, whereas the use of the non-linear method would avoid such errors.

\section{Comparative account of linear and non-linear regression method}

In this study, it is important to mention here that predicting the optimum isotherm by using only linear method is not appropriate (Yadav et al. 2014), as different forms of one single Langmuir equation may be applicable for a particular adsorption system. Subsequently, the results produced by these four equations may differ significantly as shown in Table 2. The probable reason behind unlike outcomes of different linearized forms of one equation may be the variation in derived error functions. Moreover, the error distribution may vary depending on the way of linearization. The same has been evidenced for the equilibrium sorption data of present adsorption system. However, another possible reason behind the variable results may be the different axial settings, which alter the result of linear regression and influence the determination process. Thus, it can be concluded that it is more appropriate to use nonlinear method to estimate the parameters of an isotherm or a rate equation (Kumar and Sivanesan 2007). Also, non- 

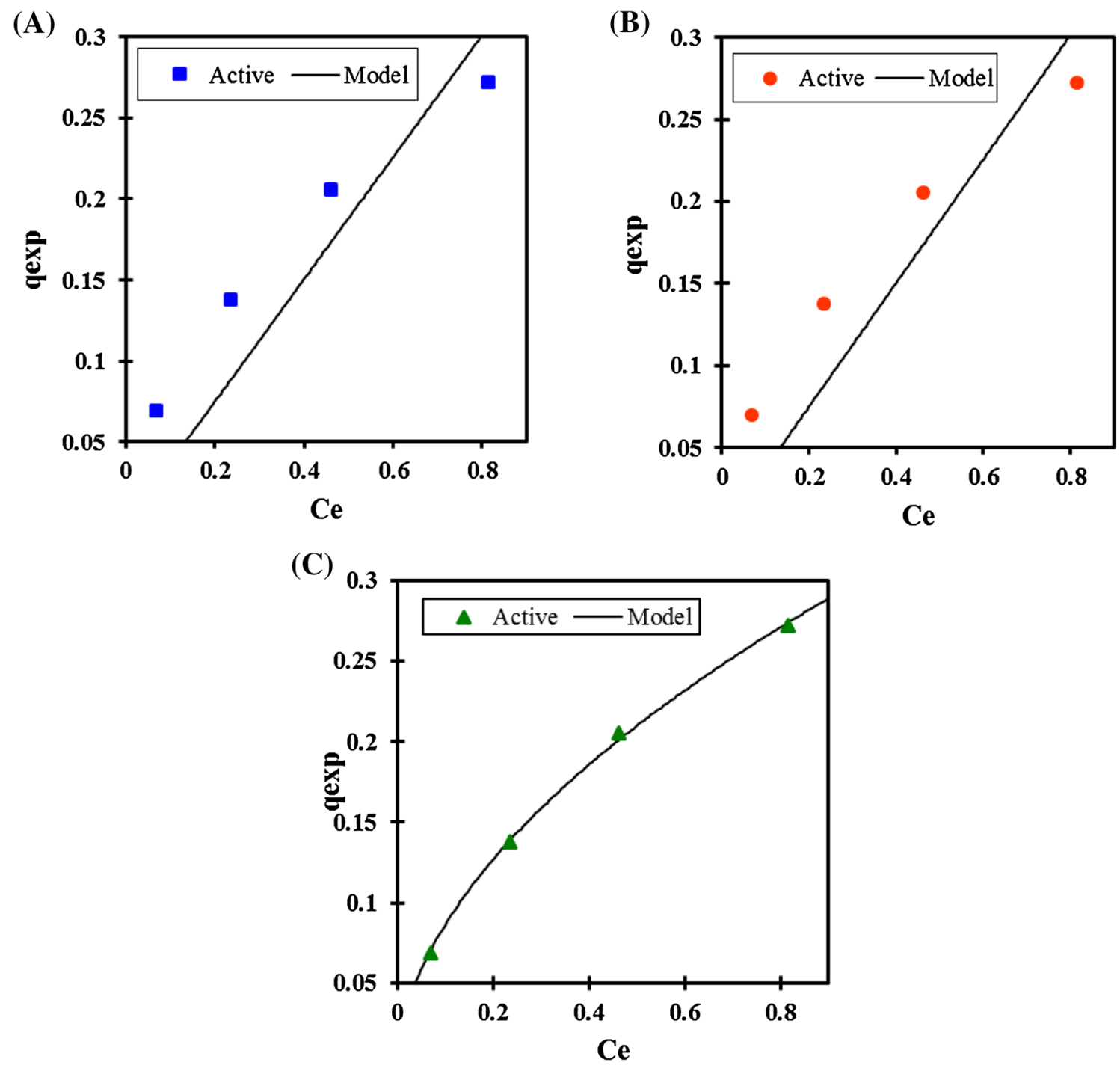

Fig. 4 Isotherms obtained using the non-linear method for the fluoride adsorption onto Bio-F: a Langmuir, b Freundlich, $\mathbf{c}$ Redlich-Peterson

linear method had an advantage that the error distribution does not get altered as in case of linear technique, because all the equilibrium parameters are fixed on the same axis.

\section{Conclusions}

Following conclusions can be drawn from this study:

- The equilibrium sorption data of F onto Bio-F sorbent is explained using the linear and non-linear forms of Langmuir, Freundlich and Redlich-Peterson isotherms.

- The comparison of linear and non-linear regression method shows that non-linear regression is more reliable as compared to linear regression method for the prediction of best-fit isotherm as well as parameter determination for the adsorption of $\mathrm{F}$ onto Bio-F.
- The values of $r^{2}$ of Langmuir-1 and Langmuir-2 presented in this study are close to those of the nonlinear form of Langmuir isotherm, while Langmuir-3 and Langmuir-4 showed almost similar $r^{2}$ values. The values of $r^{2}$ of linear forms of Freundlich isotherm were observed to be different in comparison to the value of non-linear form of the Redlich-Peterson isotherm.

- Redlich-Peterson isotherm was found to be the best-fit among the investigated isotherms suggesting that the isotherms are approaching the Freundlich, but not the Langmuir isotherm on basis of $\beta$ value which is not close to unity.

Acknowledgements The authors are thankful to Dr. A.B. Gupta for his suggestions and support in carrying out experimental work. 
Open Access This article is distributed under the terms of the Creative Commons Attribution 4.0 International License (http:// creativecommons.org/licenses/by/4.0/), which permits unrestricted use, distribution, and reproduction in any medium, provided you give appropriate credit to the original author(s) and the source, provide a link to the Creative Commons license, and indicate if changes were made.

\section{References}

Bhatnagar A, Kumar E, Sillanpää M (2011) Fluoride removal from water by adsorption-a review. Chem Eng J 171(3):811-840

Brdar M, Šćiban M, Takači A, Došenović T (2012) Comparison of two and three parameters adsorption isotherm for $\mathrm{Cr}(\mathrm{VI})$ onto Kraft lignin. Chem Eng J 183(February):108-111

Deng S, Liu H, Zhou W, Huang J, Yu G (2011) Mn-Ce oxide as a high-capacity adsorbent for fluoride removal from water. J Hazard Mater 186(2-3):1360-1366

Fan X, Parker DJ, Smith MD (2003) Adsorption kinetics of fluoride on low cost materials. Water Res 37(20):4929-4937

Foo KY, Hameed BH (2010) Insights into the modeling of adsorption isotherm systems. Chem Eng J 156(1):2-10

Ghorai S, Pant KK (2005) Equilibrium, kinetics and breakthrough studies for adsorption of fluoride on activated alumina. Sep Purif Technol 42:265-271. doi:10.1016/j.seppur.2004.09.001

Gong R, Sun Y, Chen J, Liu H, Yang C (2005) Effect of chemical modification on dye adsorption capacity of peanut hull. Dyes Pigment 67:175-181. doi:10.1016/j.dyepig.2004.12.003

Ho YS (2006a) Isotherms for the sorption of lead onto peat: comparison of linear and non-linear methods. Pol J Environ Stud 15(1):81-86

Ho YS (2006b) Second-order kinetic model for the sorption of cadmium onto tree fern: a comparison of linear and non-linear methods. Water Res 40(1):119-125

Ho YS, Chiu WT, Wang CC (2005) Regression analysis for the sorption isotherms of basic dyes on sugarcane dust. Biores Technol 96(11):1285-1291

Kamble SP, Dixit P, Rayalu SS, Labhsetwar NK (2009) Defluoridation of drinking water using chemically modified bentonite clay. Desalination 249(2):687-693

Kausar A, Bhatti HN, Sarfraz RA, Shahid M (2014) Prediction of optimum equilibrium and kinetic models for U(VI) sorption onto rice husk: comparison of linear and nonlinear regression methods. Desalination Water Treat 52(7-9):1495-1503

Khaled A, El Nemr A, El-Sikaily A, Abdelwahab O (2009) Treatment of artificial textile dye effluent containing direct yellow 12 by orange peel carbon. Desalination 238(1-3):210-232

Krishni RR, Foo KY, Hameed BH (2014) Adsorption of methylene blue onto papaya leaves: comparison of linear and nonlinear isotherm analysis. Desalination and Water Treat 52(34-36):6712-6719

Kumar KV, Sivanesan S (2007) Sorption isotherm for safranin onto rice husk: comparison of linear and non-linear methods. Dyes Pigment 72(1):130-133

Kumar KV, Porkodi K, Rocha F (2008) Comparison of various error functions in predicting the optimum isotherm by linear and nonlinear regression analysis for the sorption of basic red 9 by activated carbon. J Hazard Mater 150(1):158-165

Leyva-Ramos R, Rivera-Utrilla J, Medellin-Castillo NA, SanchezPolo M (2010) Kinetic modeling of fluoride adsorption from aqueous solution onto bone char. Chem Eng J 158:458-467. doi:10.1016/j.cej.2010.01.019

Liu Q, Guo H, Shan Y (2010) Adsorption of fluoride on synthetic siderite from aqueous solution. J Fluorine Chem 131(5):635-641

Maliyekkal SM, Sharma AK, Philip L (2006) Manganese-oxidecoated alumina: a promising sorbent for defluoridation of water. Water Res 40(19):3497-3506

Nur T, Loganathan P, Nguyen TC, Vigneswaran S, Singh G, Kandasamy J (2014) Batch and column adsorption and desorption of fluoride using hydrous ferric oxide: solution chemistry and modeling. Chem Eng J 247:93-102. doi:10.1016/j.cej.2014. 03.009

Oh GH, Park CR (2002) Preparation and characteristics of rice-strawbased porous carbons with high adsorption capacity. Fuel 81:327-336. doi:10.1016/S0016-2361(01)00171-5

Onyango MS, Kojima Y, Aoyi O, Bernardo EC, Matsuda H (2004) Adsorption equilibrium modeling and solution chemistry dependence of fluoride removal from water by trivalent-cationexchanged zeolite F-9. J Colloid Interface Sci 279(2):341-350

Pal S, Mukherjee S, Ghosh S (2013) Nonlinear kinetic analysis of phenol adsorption onto peat soil. Environ Earth Sci 71:1593-1603. doi:10.1007/s12665-013-2564-z

Shahmohammadi-Kalalagh SH, Babazadeh H (2014) Isotherms for the sorption of zinc and copper onto kaolinite: comparison of various error functions. Int J Environ Sci Technol 11(1):111-118

Tang D, Zhang G (2016) Efficient removal of fluoride by hierarchical Ce-Fe bimetal oxides adsorbent: thermodynamics, kinetics and mechanism. Chem Eng J 283:721-729. doi:10.1016/j.cej.2015. 08.019

Xiang W, Zhang G, Zhang Y, Tang D, Wang J (2014) Synthesis and characterization of cotton-like $\mathrm{Ca}-\mathrm{Al}-\mathrm{La}$ composite as an adsorbent for fluoride removal. Chem Eng J 250:423-430. doi:10.1016/j.cej.2014.03.118

Yadav M, Singh NK, Brighu U, Mathur S (2014) Adsorption of F on Bio-Filter sorbent: kinetics, equilibrium, and thermodynamic study. Desalin Water Treat 56(2):463-474

Yadav M, Tripathi P, Choudhary A, Brighu U, Mathur S (2015) Adsorption of fluoride from aqueous solution by Bio-F sorbent: a fixed-bed column study. Desalin Water Treat 57(14):6624-6631 